\title{
The Influence of Selected Marketing Strategies on the Brand Favorability: A Special Reference to the Yemeni Market
}

\author{
Fatehi Ali M. Almugari*
}

Assistant Professor at Al-Rowad University, Taiz, Yemen.

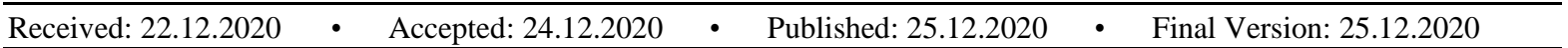

\begin{abstract}
The objective of this study is to determine the role of marketing strategies in brand favorability. It is a primary data research where data was collected through questionnaire. For analyzing purpose, AMOS and SPSS software have been used. A convenient sampling method was applied to select the respondents. The EFA is applied to construct the study dimensions. The validity and reliability were testing using the CFA outcomes. To test the hypotheses, the Structural Equation Modeling was used. The study found that, there is a positive and direct impact between distribution strategy, labeling strategy, advertising strategy, and brand favorability. Theoretically, the results can be used as a start point for making deep research in the same area. Practically, the results provide marketing managers with many suggestions for improving marketing strategies. The study results are limited only to the consumers in, small geographic area, Ibb town, Yemen.
\end{abstract}

Keywords: Key words: Brand Favorability, Distribution Strategy, Labeling Strategy, Advertising Strategy, EFA, CFA, SEM

\section{Introduction}

In the era of severe competition, increased brand favorability is an essential goal for companies to increase their market share, revenue, and customers. Today customers demand is changed according to the change in the competition. Enhancing Brand favorability is a base stone of this competition. According to Gupta et al. (2020a), "brand favorability directly and positively influences brand competitiveness in addition to building brand value". More so, the global competition led to a reduction in the product life cycle. This made more emphasis on companies to follow appropriate marketing strategies in order to enhance the favorability of their brands. According to Gupta et al. (2020b), it is important to investigate the consumer favorability toward branded and unbranded products. According to literature, favorability can be viewed as a feature, benefits, associations, or characteristics that determine the consumer attitude toward the brand (Dacin \& Smith, 1994; Dillon et al., 1986; Fuchs \& Diamantopoulos, 2010; Keller, 2003; Mahajan \& Wind, 2002).

Marketing strategies play a crucial role to direct and manage the consumers' behavior. Many studies discussed the relation between marketing strategies and brand favorability. Yusheng and Ibrahim (2018) confirmed the essential role of branding strategy in a highly competitive market. In addition, distribution strategy is another factor for enhancing brand favorability. In the same quest, Yoo et al. (2000) confirmed that intensive distribution increases consumer favorability as a result of time-saving, place utility, and reduction of sacrifices. Also, labelling strategy plays a crucial role in forming the consumers' perception toward the brand favorability (Wright, 2010).

\footnotetext{
*Corresponding Author: fatehi26@yahoo.com
} 
According to Juni and Gross (2008), the label plays a critical role in distinguishing one product from another at point of sale, especially with wide choices in branded products. In the same quest, Gialitakis and Chryssochoidis (2006) mentioned that manufacturers use many executions to differentiate their packs; these include colors, graphics, pictures, symbols, etc.

Still very few studies explore the relationship between marketing strategies and brand favorability in general and specifically in the Yemeni market. However, we found much literature about marketing strategies and consumer attitude but mostly are in developed countries' context. The authors of the present study are failed to find a study on overall marketing, affecting brand favorability among Yemeni consumers.

In contrast with previous studies, this study is an empirical study from the Yemeni consumers' perspective. This paper aims at investigating the relation between selected marketing strategies and consumer attitude toward brand favorability. We investigated many marketing strategies that may affect Yemeni consumers toward brand favorability like Intensive Distribution, Product Innovation, Customer Value-Based Pricing, and Labeling. The study provides researchers, marketers, and managers with an important glance about factors affecting consumers' brand favorability in the Yemeni market. The research into consumer behavior is still in its infancy stage in the Yemeni market. Therefore, this paper entirely based on consumer behavior aspects.

This article is structured as follows. Section tow presents literature review. Section three provides the research hypotheses and model. Section four descripts the research methodology, section five discusses the results, and section six gives the implications of the study. Section seven concludes, section eight presents implications and section nine give the limitations of the research.

\section{Literature Review}

\subsection{Brand Favorability}

Fuchs and Diamantopoulos (2010) mentioned that successful brand positioning is standing on two pillars "differentiation and favorability". The differentiation is related to the product, where the favorability is related to consumer perception toward the brand (Mahajan \& Wind, 2002). According to Dacin and Smith (1994), brand favorability means, "The brand must be accompanied by positive associations". Favorability degree determines whether the consumers have a positive associations/ characteristics toward the brand ( Dacin \& Smith, 1994; Dillon et al., 1986; Fuchs \& Diamantopoulos, 2010; Keller, 2003; Mahajan \& Wind, 2002). In addition, Keller (2003) concluded that customers perceived the brand as favorable when its features/ benefits meet their needs and want. According to Virutamasen et al. (2015) "brand association includes connecting images and symbols with a specific brand or its benefits. Furthermore, Keller (2003) determined two sources of consumer favorability for a particular brand: brand image and brand identity. Brand image is about consumer perception toward a brand, whereas, brand identity is about the brand association (Keller, 2003).

\subsection{Distribution}

According to Yoo et al. (2000), distribution strategy is effective when products are distributed in large numbers in the market. For increasing favorability level, companies may distribute selectively or exclusively rather than intensively (Yoo et al., 2000). However, consumers may be more satisfied when products are available intensively because saving time and efforts (Ferris, Oliver \& de Kluyver, 1989). According to Smith (1992), distribution strategy increases consumer satisfaction as a result of time-saving, place utility, and reduction of sacrifices. According to Burnett (2008), companies like Timex and Conca-Cola have achieved success depending on their distribution strategy. Moliner et al. (2007) confirmed that "customer perceive the high-quality products from high advertising spending, high price, good store image, and high intensive distribution". In contrast with selective distribution, intensive distribution is used to sell products in as many outlets as possible; such a strategy is fit for convenience goods (Tanner, 2012). 


\subsection{Branding}

Saeed, et. al. (2013) mentioned, "Labeling influences the consumer buying behavior, but there are some other factors also, which influence the consumer buying behavior". Wright (2010) mentioned that " Faced with the arrays of product choices at the point of sale the effective use of labeling will help to support the advertised claims". Davies and Wright, (1994) confirmed that labeling plays an important role in differentiating one product from another, especially the consumers are faced many alternative branded processed products. In the same quest, Borin et al. (2010) confirmed that, more labeling information may lead to misleading the consumers, where he found that " From over 450 foods sampled survey, 79 per cent of labels and 79 per cent of advertisements were classified as unacceptable". Similarly, the Consumer's Association in 1988, as cited in (Borin et al., 2010),stated, consumers may be confused over brand claims.

\subsection{Advertising}

Belch and Belch (2013) stated, "Advertising creativity is both original and appropriate". Belch and Belch (2012) stated, "The manner in which an advertising message is planned and executed can often lead to the ultimate success or failure of a product/ brand". Many studies found that advertising strategy could affect positively of the success of a product or a brand. Miller (1991) found that, advertising strategy has a positive influence on the purchasing intentions, brand preference, and persuasiveness. In addition, Campbell (2011) concluded, "the world's most valuable brands receive positive financial impacts due to great advertising creativity". Similarly, Sheinin et al. (2011) found that advertising strategy had a positive influence on attitude toward both short and long-term recall as well as the brand differentiation. While a study by Anderson (2004) indicates, "creative advertising for the Apple IPod broke through the clutter and generated positive publicity for the product".

\section{Study Hypotheses and Model}

This study is exploratory. The exploratory factor analysis (EFA) was used to construct dimensions of this study. Based on the outcome of the EFA, the conceptual study framework was developed, as shown in figure 1 .

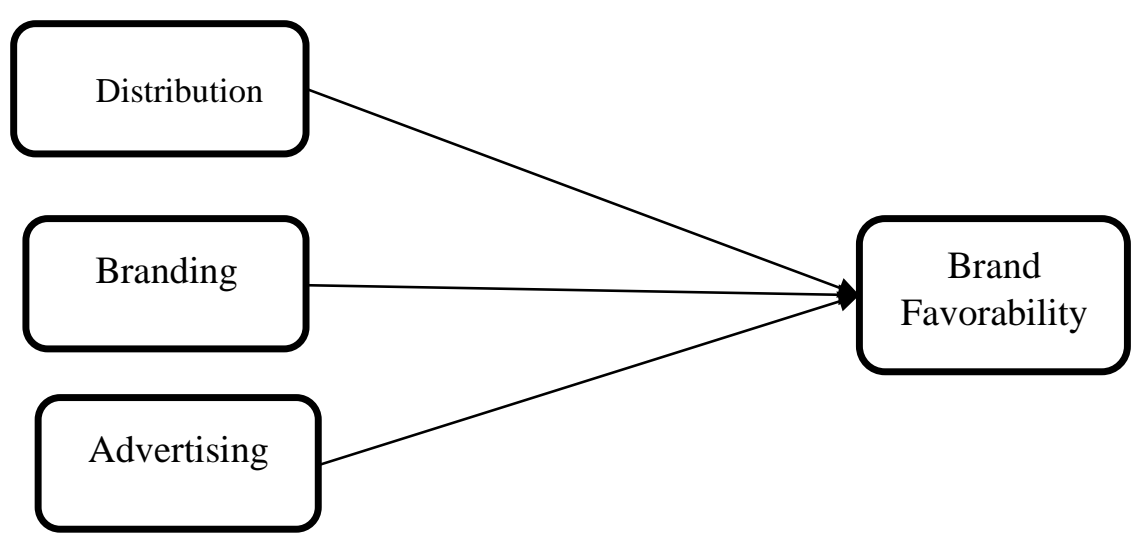

Figure 1. Conceptual model 
According to the above figure, there are three main hypotheses as to the following:

H01: The distribution strategy has no impact on the brand favorability.

H02: The branding strategy has no impact on the brand favorability.

H03: The advertising strategy has no impact on the brand favorability.

\section{Research Methodology}

This study aims to test the relationship between distribution strategy, branding strategy, advertising strategy, and brand favorability, in the context of convenience goods, in the Yemeni market. The factor analysis was applied to construct the variables of this study (Malhotra, 2007). A convenient sampling method was applied to select the participants who located in Ibb town, Yemen. In total, 600 respondents, only 488 responses were selected for further analysis. The data was analyzed using the SPSS 20.0 and AMOS 20.0 software. The hypotheses are tested using structural equation modelling (SEM). The reliability and validity are tested using the outcomes of CFA.

\section{Results and Discussions}

\subsection{Exploratory Factor Analysis (EFA)}

Exploratory factor analysis (EFA) is a powerful statistical tool to combine a set of items to measure the same construct (Kerlinger and Lee, 2000). Since the items of this study are self-constructed, the factor analysis was used to construct the related factors. In addition, EFA with CFA were used to test the validity and reliability of the questionnaire.

Pre EFA, the sample size is taken into consideration as well as the relationship between the variables (Malhotra, 2007). Therefore, KMO and Bartlett's test (Table 1) is applied.

Table 1. KMO and Bartlett's Test

\begin{tabular}{ccc}
\hline \multicolumn{3}{c}{ KMO and Bartlett's Test } \\
\hline Kaiser-Meyer-Olkin Measure of Sampling Adequacy. & .911 \\
\hline & Approx. Chi-Square & 13582.675 \\
Bartlett's Test of Sphericity & $\mathrm{df}$ & 210 \\
& $\mathrm{Sig}$. & 0.000
\end{tabular}

The KMO test is applied to test the sampling adequacy for running the EFA (Barrett et al., 2011). According to Leech et al. (2005), the KMO value should be larger than 0.50 for sampling adequacy. According to table 1 , the KMO value is 0.911 . Therefore, the sample size of this study is adequate for running the EFA. Besides (Table 1) reveals that Bartlett's Test of Sphericity is 0.000 . Therefore, the correlation matrix is significantly different from an identity matrix.

The rotated component matrix is used to show how close the relationship between the questions in variables (Sagala et al., 2014). High loadings indicate a close relationship. Table 2 contains the rotated component matrix results; there are four factors; named favorability, distribution, advertising, and branding. 
Table 2. Rotated Component Matrix

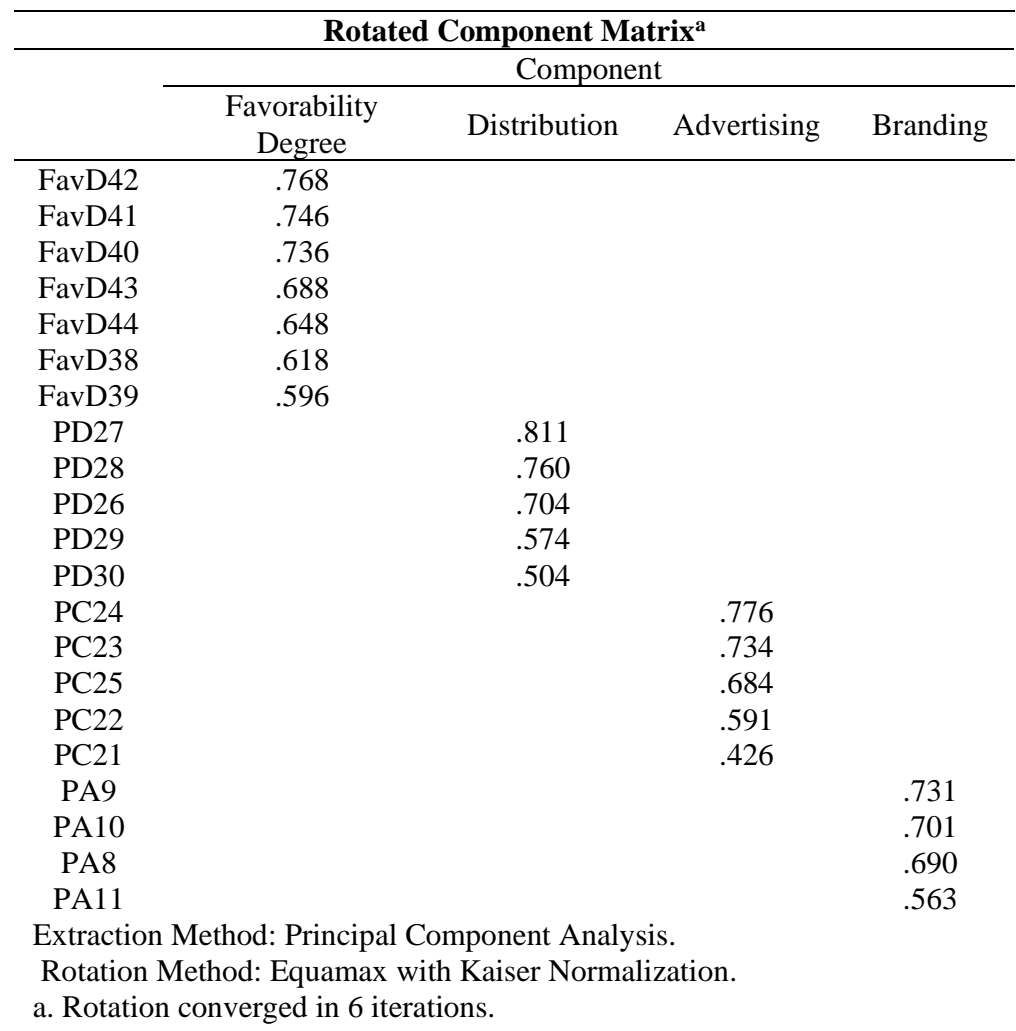

Favorability factor contains seven items with loadings ranged from 0.768 to 0.596 . Distribution factor contains five items with loadings ranged from 0.811 to 0.504 . Advertising factor contains five items with loadings ranged from 0.776 to 0.426 . Branding factor contains four items with loadings ranged from 0.731 to 0.563 .

According to table 3, the four constructed factors explained 53.787 of the total variance. The first factor explains about $17.656 \%$ of the variance. The second, third and fourth factors represent $13.232 \%, 12.173 \%$, and $10.725 \%$ respectively.

Table 3. Total Variance Explained

\begin{tabular}{cccccccccc}
\hline \multirow{2}{*}{$\begin{array}{c}\text { Compo } \\
\text { nent }\end{array}$} & \multicolumn{3}{c}{ Initial Eigenvalues } & \multicolumn{3}{c}{ Extraction Sums of Squared Loadings } & \multicolumn{3}{c}{ Rotation Sums of Squared Loadings } \\
\cline { 2 - 10 } & Total & $\begin{array}{c}\% \text { of } \\
\text { Variance }\end{array}$ & $\begin{array}{c}\text { Cumulativ } \\
\mathrm{e} \%\end{array}$ & Total & $\begin{array}{c}\% \text { of } \\
\text { Variance }\end{array}$ & $\begin{array}{c}\text { Cumulative } \\
\%\end{array}$ & Total & $\begin{array}{c}\% \text { of } \\
\text { Variance }\end{array}$ & $\begin{array}{c}\text { Cumulative } \\
\%\end{array}$ \\
\hline 1 & 6.603 & 31.443 & 31.443 & 6.603 & 31.443 & 31.443 & 3.708 & 17.656 & 17.656 \\
2 & 1.710 & 8.143 & 39.586 & 1.710 & 8.143 & 39.586 & 2.779 & 13.232 & 30.888 \\
3 & 1.520 & 7.239 & 46.825 & 1.520 & 7.239 & 46.825 & 2.556 & 12.173 & 43.061 \\
4 & 1.462 & 6.961 & 53.787 & 1.462 & 6.961 & 53.787 & 2.252 & 10.725 & 53.787
\end{tabular}

\subsection{Confirmatory Factor Analysis (CFA)}

According to Suhr (2006) confirmatory factor analysis (CFA) is "a statistical technique used to verify the factor structure of a set of observed variables. It allows the researcher to test the hypothesis that a relationship between observed variables and their underlying latent constructs exists". The factor loadings shown in EFA (table 2) were consistently confirmed in CFA (figure 2). 


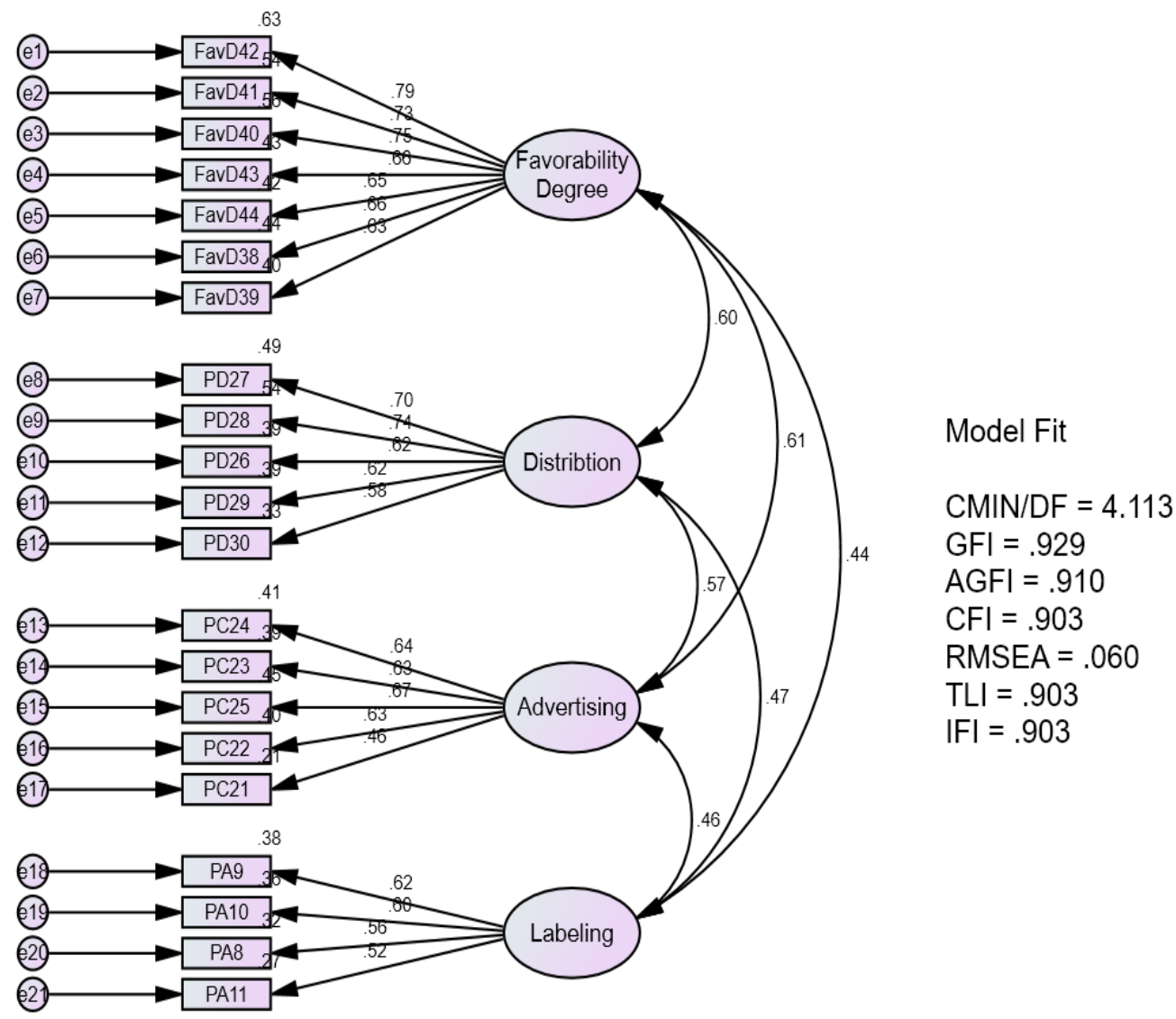

Figure 2. CFA

The overall statistics of the CFA measurement model were as follows CMIN/DF $=4.113$, Goodness of Fit Index (GFI), Adjusted Goodness of Fit Index (AGFI), Comparative Fit Index (CFI), Root Mean Square Error of Approximation ( RMSEA), TLI, IFI, were 0.929, 0.910, 0.903, 0.060, 0.903, and 0.903, respectively. These statistical values indicate a good and reasonable model fit.

\subsection{Reliability and Validity}

Joppe (2000) defined reliability as "The extent to which results are consistent over time, and an accurate representation of the total population under study is referred to as reliability, and if the results of a study can be reproduced under a similar methodology, then the research instrument is considered to be reliable". Whereas, Golafshani (2003) defined validity as "whether the means of measurement are accurate and whether they measure what they are intended to measure".

\subsection{Construct validity}

Hair et al. (2010) suggested two methods for testing construct validity; convergent validity and discriminant validity. Convergent validity assumes that items that are indicators of a specific construct should share a high proportion of variance in common (Golafshani, 2003). The AVE was used to test the convergent method. The role of thumb is that AVE values of 0.5 or higher indicate a good convergent validity (Hair et al. 2010). In addition, discriminant validity refers to the extent to which constructs are distinct (Kemp et al., 2012). It is proved by comparing Maximum Shared Variance (MSV) with AVE for each construct (Kemp et al., 2012). MSV 
is the square of inter-correlation between two constructs (factors). If MSV is less than AVE, the discriminant validity is confirmed (Fornell \& Larcker, 1981).

Table 4. Reliability and Convergent Validity

\begin{tabular}{lccc}
\hline \multicolumn{1}{c}{ Vareiabls } & CR & AVE & MSV \\
\hline Advertising & 0.749 & 0.578 & 0.377 \\
Favorability Degree & 0.873 & 0.500 & 0.377 \\
Distribution & 0.800 & 0.547 & 0.373 \\
Labeling & 0.778 & 0.546 & 0.221
\end{tabular}

Table 5. Factor correlation matrix with the square root of the EVA

\begin{tabular}{ccccc}
\hline $\operatorname{MaxR}(\mathbf{H})$ & Advertising & Favorability Degree & Distribution & Labeling \\
\hline 0.761 & $\mathbf{0 . 6 1 5}$ & & & \\
0.881 & 0.614 & $\mathbf{0 . 7 0 5}$ & & \\
0.813 & 0.598 & 0.611 & $\mathbf{0 . 6 6 9}$ & \\
0.682 & 0.470 & 0.467 & 0.450 & $\mathbf{0 . 5 8 8}$
\end{tabular}

\subsection{Hypotheses Testing and Interpretation}

The hypotheses and structural model were evaluated after attaining a well-validated measurement model. The model fit is reliable and valid satisfactory where CMIN/DF is 4.112, Goodness-of-Fit Index (GFI) is 0.925, AGFI is 0.905 , CFI is 0.902 , RMSEA is 0.062 , and IFI is .903. Therefore, the structural model analyzed is fit where all the Goodness of fit statistics were acceptable.

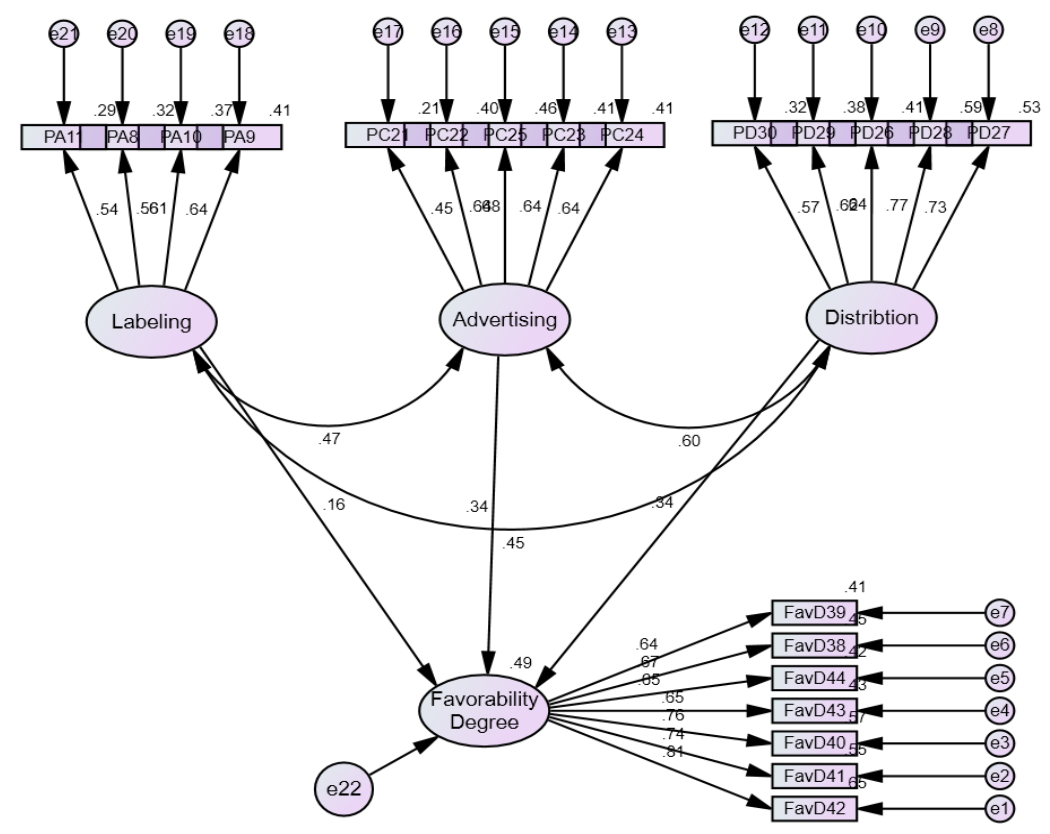

Figure 3. SEM

The relationship between variables is evaluated using structural equation modelling (SEM). The SEM determined the selected marketing strategies (labeling, Advertising, and distribution) as exogenous variables. These exogenous variables are matching to one endogenous variable (brand favorability). 
The results show that all the hypotheses, suggested in this study, are supported. H01 shows a direct impact of distribution strategy on brand favorability $(\beta=0.467, \mathrm{t}=10.02, \mathrm{p}=.000)$. The $\beta$ value $=0.467$ indicates that distribution strategy affects the dependent variable brand favorability by about 46 per cent. Therefore, a 1 per cent increase in distribution strategy will result in a 46 per cent improvement in brand favorability. The t-value $(\mathrm{t}=10.02)$ and $\mathrm{p}$-value $(\mathrm{p}=0.000)$ reveal the positive and direct relationship between distribution strategy and brand favorability.

Second hypothesis, the impact of labeling strategy on brand favorability, was also supported $(\beta=0.195, \mathrm{t}=$ $5.002, \mathrm{p}=0.000$ ). The $\beta$-value 0.195 indicates that labeling strategy influences the dependent variable brand favorability by about 19 per cent. Therefore, a 1 per cent increase in labeling strategy would result in a 19 per cent improvement in brand favorability. The $t$-value $(t=5.002)$ and $p$-value $(p=0.000)$ also indicate the positive and direct relationship between labeling strategy and brand favorability.

The third hypothesis, the impact of advertising strategy on brand favorability, was also supported $(\beta=0.445$, $\mathrm{t}=9.339, \mathrm{p}=0.000)$. The $\beta$-value 0.445 indicates that advertising strategy influences the dependent variable brand favorability by about 44 per cent. Therefore, a 1 per cent increase in advertising strategy would result in a 44 per cent improvement in brand favorability. The $t$-value $(t=9.339)$ and $p$-value $(p=0.000)$ also indicate the positive and direct relationship between advertising strategy and brand favorability.

The $\mathrm{R}^{2}$ (0.487) indicates that, overall, the independent variables, distribution strategy, labeling strategy, and advertising strategy predicted the dependent variable brand favorability by 48.7 per cent (Table 6). Therefore, the error variance of brand favorability is approximately 52.3 per cent of the total variance.

Table 5. Hypotheses Testing Results

\begin{tabular}{cccccccc}
\hline \multicolumn{7}{c}{ Regression Weights: (Group number 1 - Default model) } \\
\hline & Path & & Estimate & S.E. & C.R. & P & Decision \\
\hline Favorability Degree & $<---$ & Distribution & 0.467 & 0.047 & 10.02 & $* * *$ & Reject \\
Favorability Degree & $<---$ & Labeling & 0.195 & 0.039 & 5.002 & $* * *$ & Reject \\
Favorability Degree & $<---$ & Advertising & 0.445 & 0.048 & 9.339 & $* * *$ & Reject \\
$R^{2}$ & & & & 0.487 & &
\end{tabular}

\section{Discussion}

The study found a positive and significant relation between distribution strategy and brand favorability. This finding is in line with Ferris et al. (1989), Smith (2000), and Moliner et al. (2007) who found that effective distribution strategy led to enhancing consumers' favorability due to saving time, efforts, place utility, and reduction of sacrifices.

Furthermore, the study revealed a positive and significant relationship between labelling strategy and brand differentiation. In the same quest, Talebnejad et al. (2019) found that illustrate some color and shape attributes play a significant role in the perception of Iranian consumers toward selecting a brand. Furthermore, Gulzira and Han (2019) mentioned that labeling is a psychological factor that shapes consumer's behavior and their decision. They found a positive and significant relation between labeling strategy and brand favorability.

Also, the study found that advertising strategy has a positive and direct impact on brand favorability. This result is consistent with the results of Belch and Belch (2012), who found that advertising message, may lead to the failure or success of a product or a brand. Furthermore, this finding is consistent with findings of Sheinin et al. (2011) who found that effective advertising strategy has a positive impact on consumer attitude and brand favorability.

\section{Conclusion}

The study investigated many marketing strategies that may affect Yemeni consumers toward brand favorability like distribution strategy, labeling strategy, and advertising strategy. The study provides researchers, 
marketers, and managers with an important glance about factors affecting consumers' brand favorability in the Yemeni market. A convenient sampling method was applied to select the participants who located in Ibb town, Yemen. In total, 600 respondents, only 488 responses were selected for further analysis after the initial data cleaning and screening. The study found that distribution strategy, labeling strategy, and advertising strategy have a significant and positive impact on the brand favorability. Theatrically, this study supported by previous studies in the same field. In addition, the findings of this study will benefit the researchers in emerging markets like Yemeni market. Practically, this study provides marketers and manufactures of convenience goods, in Yemeni market, the essential factors affecting the consumers toward brand favorability.

\section{Study Implications}

Theoretically, the results will add to previous findings on the marketing strategies and its impact on brand favorability. This study is a start point for Yemeni researchers to do more investigation in the same field. In addition, the questionnaire of this study is valid and reliable; therefore, academicians can use it for the similar studies.

Practically, based on the findings, the researcher proposes the following contributions for marketers, manufacturer, and researchers. Manufactures should make more effort to promoting labelling and pricing strategies. We suggest crucial elements, for improving labelling strategy, like using appropriate images, symbols, clear instructions and information. In addition, the study model predicts only 48.7 percent of the variance of brand favorability; we suggest that researchers do more research on the factors affecting brand favorability. Also, the questionnaire of this study is valid and reliable, and it can be used for similar studies. The study provides an evidence from low-income country. Various studies pointed out that there is a need to examine different issues in emerging and low-income countries (e.g., Al Maqtari et al., 2020, Farhan et al., 2020; Hashed \& Almaqtari, 2020). Accordingly the present study provides an insight that similar studies could be conducted in different other emerging and low-income countries contexts.

\section{Limitations}

The convenience sampling method was used for collecting data, which has many limitations like lack of findings generalization. Future studies can use other sampling methods like judgmental sampling and random simple sampling methods. The second limitation is that the study model interprets only about $48.7 \%$ of the total variance of brand favorability; we consider this as a research gap for future studies. . In addition, future studies can expand the geographical area of respondents. Furthermore, future studies can investigate why consumer prefer some specific brands to other brands of the same product. 


\section{References}

[1] Al Maqtari, F. A., Farhan, N. H., Al-Hattami, H. M., \& Khalid, A. S. (2020). Impact of country-level corporate governance on entrepreneurial conditions. Cogent Business \& Management, 7(1), 1797261. https://doi.org/10.1080/23311975.2020.1797261

[2] Barrett, K.C., Morgan, G.A., Leech, N.L. and Gloeckner, G.W. (2011) 'IBM SPSS for introductory statistics: Use and interpretation'. Routledge.

[3] Belch, G. E., \& Belch, M. A. (2012). Advertising and promotion: An integrated marketing communications perspective. Burr Ridge, IL: McGraw Hill-Irwin.

[4] Belch, M. A., \& Belch, G. E. (2013). The Future of Creativity In Advertising. Journal of Promotion Management19(4), Pages 395-399. http://doi.org/10.1080/10496491.2013.817219

[5] Borin, N., Cerf, D. C., \& Krishnan, R. (2010). Consumer effects of environmental impact in product labeling. Journal of Consumer Marketing.

[6] Burnett, J. (2008) 'Core Concepts of Marketing. The Global Text Project', Funded by the Jacobs Foundation, Zurich, Switzerland., 1-298.

[7] Campbell, E. (2011). Evidence proves the future is now: Why great creative needs great research. Journal of Advertising Research, 51(1), 222-223.

[8] Dacin, P. A. and Smith, D. C. (1994) 'The Effect of Brand Portfolio Characteristics on Consumer Evaluations of Brand Extensions', Journal of Marketing Research, 31, 229-42.

[9] Davies, M. A. P., \& Wright, L. T. (1994). The Importance of Labelling Examined in Food Marketing. European Journal of Marketing, 28(2), 57-67.

[10] Dillon, R., W., Domzal, T. and Madden, T. J. (1986) 'Evaluating Alternative Product Positioning Strategies', Journal of Advertising Research, (26), 29-35.

[11] Farhan, N., Tabash, M., Almaqtari, F., \& Yahya, A. (2020). Board composition and firms' profitability: Empirical evidence from pharmaceutical industry in India. Journal of International Studies, 13(3), 180194. https://doi.org/10.14254/2071- 8330.2020/13-3/12

[12] Ferris, Paul, James Oliver, and Cornelis de Kluyver, (1989), "The Relationship Between Distribution and Market Share." Marketing Science 8 (2): 107-127.

[13] Fornell, C., \& Larcker, D. F. (1981). Evaluating structural equation models unobservable variables and measurement error. Journal of Marketing Research, 18(1), 39-51.

[14] Fuchs, C. and Diamantopoulos, A. (2010) 'Evaluating the effectiveness of brand-positioning strategies from a consumer perspective', European Journal of Marketing, 44(11/12), 1763-1786. http://scihub.tw/10.1108/03090561011079873

[15] Gialitakis, G. and Chryssochoidis, G. (2006) 'Schoolchildren's understanding of food labels', Young Consumers, 7(4), 19-25.

[16] Golafshani, N. (2003) 'Understanding reliability and validity in qualitative research', The Qualitative Report, 8(4), 597-607. http://sci-hub.tw/10.3367/UFNr.0180.201012c.1305

[17] Gulzira, Z. and Han, S.L. (2019) 'Labeling and Customer Loyalty: Mediating Effects of Brand-related Constructs', Asia Marketing Journal, 20(4), 65-94.

[18] Gupta, S., Bisaria, C. and Gupta, S. (2020b) 'Discovering consumer preference and their satisfaction level towards branded and unbranded paints', International Journal of Business Excellence, 21(3), 316-330.

[19] Gupta, S., Gallear, D., Rudd, J. and Foroudi, P. (2020a) 'The impact of brand value on brand competitiveness' Journal of Business Research, 112, 210-222.

[20] Hair Jr, J. F., Black, W. C., Babin, B. J., Anderson, R. E. and Tatham, R. L. (2010) 'SEM: An introduction', Multivariate data analysis: A global perspective, 629-686.

[21] Hashed, A., \& Almaqtari, F. (2020). The impact of corporate governance mechanisms and IFRS on earning management in Saudi Arabia. Accounting, 7(1), 207-224. https://doi.org/10.5267/j.ac.2020.9.015

[22] Joppe, M. (2000). The Research Process. Retrieved February 25, 1998, from http://www.ryerson.ca/ mjoppe/rp.htm

[23] Juni, S., and Gross, J. S. (2008) 'Emotional and persuasive perception of fonts', Perceptual and Motor Skills, 106(1), 35-42.

[24] Keller, K. L. (2003) 'Strategic Brand Management (2nd ed.)'. New Jersey: Prentice Hall. 
[25] Kemp, E., Bui, M. and Chapa, S. (2012) 'The role of advertising in consumer emotion management], International Journal of Advertising, 31(Kacen 1994), 339-353. http://sci-hub.tw/10.2501/IJA-31-2-339$\underline{353}$

[26] Kerlinger, F. N. and Lee, H. B. (2000) 'Survey research', Foundations of Behavioral Research, 4, 599-619

[27] Leech, N.L., Barrett, K.C., Morgan, G.A., Clay, J.N. and Quick, D. (2005) 'SPSS for intermediate statistics: Use and interpretation'. Mahwah, NJ: Lawrence Earlbaum Associates. Inc., Publishers.

[28] Mahajan, V. and Wind, Y. (2002) 'Got emotional product positioning?', Marketing Management, 11(3), 36-41.

[29] Miller, C. (1991, January 7). Study says "likability" surfaces as measure of TV ad message usefulness on brand judgments. Journal of Advertising, 40(1), 5-17.

[30] Moliner, M. A., Sánchez, J., Rodríguez, R. M. and Callarisa, L. (2007) 'Perceived relationship quality and post-purchase perceived value: An integrative framework', European Journal of Marketing, 41(11/12), 1392-1422.

[31] Saeed, R., Lodhi, R.N., Iqbal, A., Nayyab, H.H., Mussawar, S. and Yaseen, S. (2013) 'Factors influencing job satisfaction of employees in telecom sector of Pakistan', Middle-East Journal of Scientific Research, $16(11), 1476-1482$.

[32] Sagala, C., Destriani, M., Putri, U.K. and Kumar, S. (2014) 'Influence of promotional mix and price on customer buying decision toward fast food sector: a survey on university students in jabodetabek (Jakarta, Bogor, Depok, Tangerang, Bekasi) Indonesia', International Journal of Scientific and Research Publications, 4(1), 2250-3153.

[33] Schmitt, B. and Zarantonello, L. (2013), "Consumer Experience and Experiential Marketing: A Critical Review", Malhotra, N.K. (Ed.) Review of Marketing Research (Review of Marketing Research,10, Emerald Group Publishing Limited, Bingley, 25-61

[34] Sheinin, D. A., Varki, S., \& Ashley, C. (2011). The differential effect of ad novelty and message usefulness on brand judgments. Journal of Advertising, 40(3), 5-18.

[35] Smith, D.C. (1992) 'Brand extensions and advertising efficiency: What can and cannot be expected'. Journal of Advertising Research. 32(6), 11-20.

[36] Suhr, D. D. (2006) 'Exploratory or Confirmatory Factor Analysis?'. Proceedings of the Thirty-First Annual SAS Users Group International Conference,1-17. http://sci-hub.tw/10.1002/da.20406.

[37] Talebnejad, A., Ranjbarian, B., Bidram, H. and Samavatian, H. (2019) 'Colour associations of archetypes: lessons for brands', International Journal of Business Excellence, 19(1), 16-43.

[38] Tanner, J. and Raymond, M.A., (2012) 'Marketing principles". Creative Commons. Retrieved February, 12, p.2014.

[39] Virutamasen, P., Wongpreedee, K. and Kumnungwut, W. (2015) 'Strengthen Brand Association through SE: Institutional Theory Revisited', Procedia - Social and Behavioral Sciences, 195, 192-196. http://scihub.tw/10.1016/j.sbspro.2015.06.348

[40] Wright, L. T. (2010) 'Exploring the need for extended research : an investigation of consumer attitudes to product labeling', Journal of Product and Brand Management, . 6(6), 417-427.

[41] Wright, L. T. (2010) 'Exploring the need for extended research : an investigation of consumer attitudes to product labeling', Journal of Product and Brand Management, . 6(6), 417-427.

[42] Yoo, B., Donthu, N. and Lee, S. (2000) 'An Examination of Selected Marketing Mix Elements and Brand Equity', Journal of the Academy of Marketing Science, 28(2), 195-211. http://scihub.tw/10.1177/0092070300282002

[43] YuSheng, K. and Ibrahim, M. (2019) 'Service innovation, service delivery and customer satisfaction and loyalty in the banking sector of Ghana', International Journal of Bank Marketing. 37 (5), 1215-1233. http://sci-hub.tw/10.1108/IJBM-06-2018-0142 